\title{
ARTES VISUAIS E FEMINISMOS: IMPLICAÇÕES PEDAGÓGICAS
}

\author{
Andréa Senra Coutinho \\ Universidade Federal de Juiz de Fora \\ Luciana Gruppelli Loponte \\ Universidade Federal do Rio Grande do Sul
}

\begin{abstract}
Resumo: Qual o sentido de tratarmos da relação entre artes visuais e feminismos hoje? Quais os efeitos possíveis dessa discussão nas práticas contemporâneas de ensino de arte? Essas e outras indagações permeiam este artigo, que pretende trazer à tona um tema ainda marginal, quase invisível em nossas principais preocupações pedagógicas em relação à arte e às práticas docentes, invisibilidade essa decorrente também da escassa produção teórica a respeito, em especial, em língua portuguesa. As discussões apresentadas neste artigo emergem principalmente de pesquisas realizadas por Loponte $(2002,2005,2008,2010)$ e Coutinho $(2010$, 2011). Ao levantar questionamentos que entrelaçam artes visuais e feminismos, ou a ideia de uma arte perpassada pelas intenções feministas, propomos um olhar mais atento para as práticas pedagógicas que não se eximem de incorporar tais discussões, mas ainda parecem estar letárgicas para essa e outras abordagens mais provocativas e descondicionantes no contexto escolar. Ao final, pretendemos chamar a atenção para a necessidade de uma análise crítica envolvendo um trabalho voltado ao ensino da arte produzida por mulheres na contemporaneidade em espaços escolares, apresentando algumas argumentações favoráveis a esse empreendimento docente.

Palavras-chave: arte; artistas mulheres; educação; escola.
\end{abstract}

\section{Introdução}

Qual o sentido de tratarmos da relação entre artes visuais e feminismos hoje? Quais os efeitos possíveis dessa discussão nas práticas contemporâneas de ensino de arte? Essas e outras indagações permeiam este artigo, que pretende trazer à tona um tema ainda marginal, quase invisível em nossas principais preocupações pedagógicas em relação à arte e às práticas docentes, invisibilidade essa decorrente também da escassa produção teórica a respeito, em especial, em língua portuguesa. As discussões apresentadas neste

Copyright @ 2015 by Revista Estudos Feministas. 
artigo emergem principalmente de pesquisas realizadas por Luciana Loponte e Andréa Coutinho nos últimos anos. Inicialmente, apresentamos a discussão que entrelaça arte contemporânea, feminismos e mulheres artistas, abordando também o desgaste do adjetivo feminista relacionado às artes visuais para, ao final, apontar as contradições e implicações pedagógicas na relação entre arte e feminismo. Nesse sentido, pretendemos chamar a atenção sobre a necessidade de uma análise crítica envolvendo um trabalho voltado ao ensino da arte produzida por mulheres na contemporaneidade em espaços escolares, apresentando algumas argumentações favoráveis a esse empreendimento docente.

\section{Arte contemporânea, feminismos e mulheres artistas}

A revisão da condição da mulher, motivada pelos crescentes estudos que se seguiram ao movimento feminista, assinalou o início da luta pelos direitos da mulher ocidental. Os hábitos e costumes femininos, o comportamento, a sexualidade e o corpo, analisados pelo crivo dos estudos da mulher, feministas e de gênero, de lá para cá, tornaram-se objetos de pesquisa de inúmeras investigações e intervenções, estando também incluídas as atividades realizadas pelas mulheres no campo artístico.

O impacto do feminismo, simultaneamente à luta dos homossexuais e negros - as chamadas minorias - e a emblemática interrogação plantada por Linda Nochlin:" "Por que não há grandes artistas mulheres?" geraram, tal como denuncia o Grupo Guerrilla Girls, uma série de outras perguntas, remanescentes de incômodos antigos, como: "Por que da desvalorização das mulheres artistas no mercado?" "Onde estão as grandes mestras?" "As mulheres têm que estar nuas para entrar nos museus?". E mais: por que a porcentagem de mulheres que ocupa galerias e museus é inferior a 10\%? Há um número menor de mulheres produzindo arte do que homens? É por isso que elas supostamente aparecem menos? As mulheres não são citadas ou são pouco mencionadas pela história da arte, pela crítica e suas adesões institucionais (museus, galerias, coleções, publicações etc.) porque suas proposições não têm integridades e qualidades artísticas?

Essas e outras desconfianças formaram o rol reivindicativo levantado por algumas artistas mulheres em plena ação nos anos 60/70, reiterado pelas lutas feministas e ancorado numa crítica teórica que também se impunha. Uma nova sensibilidade despontava, e os sinais emitidos por trajetórias de artistas, como Eva Hesse, Louise Bourgeois, Ana Mendieta, Nikki de Saint Phalle e Meret Oppenheim, contribuíram para a abertura do debate crítico frente ao poder patriarcal no campo artístico quando prenunciaram inquietações e dúvidas em suas próprias obras de arte e através de suas posturas no mercado e na vida.

É preciso ressaltar que muitos artistas, e não somente mulheres, dialogavam com as atuações de Marcel Duchamp, com os interesses da arte conceitual e presenças como as de Jasper Johns, Robert Rauschenberg, Yves Klein e Manzoni. No caso brasileiro, Lygia Clark, Lygia Pape e Hélio Oiticica ajudaram a anunciar as bases da produção contemporânea.

Como beneficiárias desse legado e fortemente embaladas pelas crescentes lutas para a emancipação e igualdade no terreno social, combatentes de conflitos culturais como racismo, militarismo e homofobia, em oposição acirrada contra o poder falocrático na vida e na arte, artistas mulheres dos anos 60/70 fizeram de suas obras estandartes do ponto de vista dos interesses feministas. Elas abraçaram com tenacidade a causa apresentando proposições artísticas que focavam o controle do próprio corpo, o fortalecimento de uma identidade própria, a sexualidade, a maternidade, a violência contra mulheres, os padrões impostos socialmente, a violação, a alienação do trabalho doméstico, a dupla jornada de trabalho, os estereótipos femininos difundidos pelas mídias

'Linda NOCHLIN, 1971. 
e outras temáticas recorrentes. Um novo panorama começava a se descortinar na arte, uma paisagem feminista, pessoal e surpreendente, como diz Michel Rush. ${ }^{2}$

É importante salientar que o impacto do feminismo na arte trouxe à luz uma série de enunciados artísticos que tratavam diretamente do universo singular da mulher sob o ponto de vista da própria mulher artista - naquela altura mais ciente, desperto e afinado. Uma arte feita por mulheres e a propósito delas, recheada de intenções políticas, não foi aceita nem completamente compreendida no início do movimento. A postura de engajamento, o tom ácido, crítico e politizado das ações empreendidas foram considerados radicais em seu começo e recebidos com resistência.

Uma série de estratégias de ação foi adotada: a primeira, e talvez a principal, foi delatar e combater o androcentrismo das abordagens artísticas tradicionais, denunciando sua influência nos espaços de exibição de arte, entre curadores e diretores de museus. O radicalismo empreendido (e necessário naquela época diante da forte exclusão sofrida pelas artistas) serviu para forçar um sistema patriarcal bastante sedimentado e enraizado na arena artística, mas ocasionou certo sectarismo, pois projetos como periódicos e grupos de discussão organizados pelas artistas eram fechados e afastavam, de maneira geral, os homens. Esse separatismo inicial imposto pôde ser entendido como ações "mais duras" e também como uma espécie de autoproteção contra o discurso masculino. Mas isso acabou por demonstrar algumas tentativas de substituição de um discurso totalitário por outro uma das críticas desfavoráveis à iniciativa.

Outra meta importante foi ultrapassar e superar os clichês de feminilidade. Num rápido exame do percurso da história da arte ocidental, é recorrente a representação da mulher como "objeto de desejo", "objeto de beleza", "de perdição", "santificação e pureza" sob o crivo do olhar androcêntrico. Essas são formas de representação imputadas às mulheres por longo tempo - bem como o papel de modelo e musa - que passam a ser recusadas pelas artistas em favor da potencialização da capacidade criadora e da ocupação do lugar de sujeito na produção cultural.

O terceiro alvo, de cunho arqueológico, objetivou dar visibilidade e voz à artista muIher, desocultando nomes esquecidos e/ou marginalizados pela história e crítica da arte. 0 trabalho não era pouco, mas graças aos protestos eficazes e à pressão exercida pelas artistas mulheres, gradativamente, o rechaço e a exclusão foram cedendo cada vez mais espaços ao discurso feminino e feminista na arte, aumentando os convites e a atenção sobre elas.

Várias frentes se aliaram às artistas, inclusive as investigadoras acadêmicas interessadas em apregoar os binômios arte-mulher, feminismo-arte e que, até hoje, vêm acrescentando dados e dirigindo suas buscas para diversos campos, como o da história, sociologia, filosofia, arqueologia, educação, psicanálise, política e antropologia, interrelacionando-os com arte e feminismo. Elas são colaboradoras na minimização do déficit no meio acadêmico e editorial sobre a história das mulheres, estando empenhadas em engrossar a teoria e a análise crítica em torno da arte e da mulher.

Vale notar que, quando a identidade feminina passa a ser o foco de interesse de grupos de artistas mulheres (por volta dos anos 60/70), percebe-se numa parcela de produções uma abordagem essencialista, ou seja, a ideia da existência de características peculiares atribuídas a um feminino que distinguiria mulheres de homens. A procura por fontes e imagens de si mesma, calcada na crença de uma essência feminina, a busca por uma parte do corpo da mulher que representasse essa diferença, como nas peças em porcelana (pratos que remetem às vulvas) que fizeram parte da instalação The dinner party, de Judy Chicago (1974-79), configuraram uma iconografia explorada no início do

${ }^{2}$ Michel RUSH, 2006. 
movimento. Porém, segundo Whitney Chadwick, ${ }^{3}$ muitas feministas reagiram contrárias a essa centralização imaginária no útero ou na vagina, entendendo esse procedimento como outra forma de fixação e determinação da feminilidade. A noção de essência feminina imutável e fixa era suporte de um determinismo biológico que começou a contrastar com as teorias do construtivismo social, o qual defendia as instabilidades nas significações culturais e a interpretação multicultural do gênero.

Vale acrescentar a essa discussão que uma das grandes lutas do feminismo, desde as sufragistas, foi por uma "igualdade" entre mulheres e homens. Porém, o conceito de "iguais" foi confundido com uma reação de espelhamento das posturas masculinas. Essa apropriação do universo masculino, uma espécie de androgenia, foi sentida por algumas mulheres como forma de conquista social. No entanto, essa conduta acabou por ser considerada equivocada e rechaçada pela crítica e, até mesmo, por outras artistas. Afinal, desembocava numa substituição ou duplo do homem, e tanto a abordagem essencialista como a androgenia trouxeram poucas mudanças, pois reforçavam os aspectos masculinos como prioritários e modelos a serem seguidos, preservando as dicotomias pertencentes a esse território.

Desacreditada, a abordagem essencialista na arte não avançou muito, e novas concepções mais sofisticadas em torno da construção social dos papéis de feminilidade e masculinidade, com a entrada dos anos 80 , vieram contribuir com noções mais plurais e menos dicotômicas sobre ser mulher e ser homem no mundo pós-moderno.

A concepção de feminilidade como construção cultural gerou, por parte de várias artistas, outra compreensão a respeito dos processos naturalizantes e condicionantes que as tornaram não somente portadoras, mas também reprodutoras de normatizações a partir do ponto de vista patriarcal. O que também permitiu, em contrapartida, um autorreconhecimento como sujeitos e produtoras de significados.

As artistas trabalharam numa espécie de rebelião pessoal e social, contrária aos convencionalismos condicionantes. Era preciso deflagrar com honestidade os abusos, as agressões, as subordinações, os quais as próprias mulheres, de certa maneira, ajudaram a constituir, e dar a isso um tom crítico e não vitimista. Esse processo contribuiu para que inúmeras obras de arte, ao longo dos tempos, apresentassem temáticas visuais da mulher simbolizando um referencial universal de uma identidade feminina não afirmada pelas mulheres, mas idealizada sob as lentes masculinas.

A revisão e análise cada vez mais consistente da participação artística, social, cultural, política e econômica da mulher, as criações de representações alternativas, plurais e diferenciadas de ser mulher na atualidade, bem como a desestabilização dos modelos deterministas do passado, são algumas das reflexões norteadoras na produção dos anos 90 em diante.

Os clichês do feminino na arte, assim como na mídia e nos meios de comunicação em geral, foram reavaliados, sendo investigados e postos em xeque por artistas contemporâneas que se atrevem a ironizar posturas e comportamentos padronizados em suas proposições. De algum modo, as proposições artísticas de algumas mulheres constituemse como formas de resistência em que as pessoalidades, particularidades e biografias são apresentadas em projetos de transgressão e alerta, como se pode conferir em parte da produção de Louise Bourgeois, Nan Goldin, Sophie Calle, Marina Abramovic e outras. Algumas obras revelam a história de vida da própria artista, as vivências pessoais e a intimidade transformadas em experiência estética.

Outras artistas fazem de suas experiências corporais e rituais, ditos próprios do feminino (como pintar cabelos, cuidar dos afazeres domésticos etc.), motivadores para a criação de

${ }^{3}$ Whitney CHADWICK, 1999.

184 Estudos Feministas, Florianópolis, 23(1): 181-190, janeiro-abril/2015 
performances, vídeos, instalações etc. Sacrifícios, sofrimentos, renúncias, abdicações femininas são expostos abertamente, como em Loving Care, performance realizada em 1992 por Janine Antoni. Ao pintar o chão da galeria com os próprios cabelos, transformandoos em pincel e esfregão ao mesmo tempo, a artista compartilha e torna público o que antes era privado, invisibilizado como natural e irrevogável para as mulheres.

Quanto aos aparatos e recursos técnicos utilizados, as artistas têm optado por inovar na utilização de meios expressivos como vídeos, instalações, fotografias, performances, mas não deixaram de utilizar gravuras, esculturas, desenhos e pinturas. E, nesse roteiro poético, outros materiais não artísticos foram introduzidos: rendas, agulhas, absorventes, fraldas, mamadeiras, cabelos, maquiagens, tecelagens, vestimentas, roupas íntimas, leite, menstruação, entre outros.

Em síntese, a arte em interlocução com os feminismos, como tendência contemporânea, é resultante de inúmeras inquietações germinadas na contínua resistência e transgressão ao sistema social e político unifocal. Hoje, as artistas estão convictas de sua presença e papel como sujeito na arte, na história e na vida.

\section{O adjetivo feminista para a arte: sobre 0 desgaste dos termos}

O perigo hoje da utilização de nominalismos e taxonomias é reproduzir posturas teóricas mais duras do passado que, ao fornecerem uma sistematização que abarcava um determinado tema através de classificações e periodizações, causavam sérias reduções e muitas exclusões. Logo, o desgaste das expressões "artista feminista" e "arte feminista" foi inevitável. Em decorrência de resquícios de paradigmas guetizadores e periodizadores inoperantes, a tendência ao desuso é também resultado da rejeição de artistas atuais que encaram esses termos como duvidosos, oscilantes e enganosos. Isso se deve em parte a alguns clichês e mitos do passado. A antiga herança das representações gráficas das primeiras feministas ou sufragistas, por exemplo, em fins do século XIX e inícios do XX, tinham as primeiras militantes caricaturizadas e ridicularizadas como mulheres dominantes, histéricas e amargas. "Abruptas", "agressivas" ou "feias", só restava às feministas, segundo esse ponto de vista, associarem-se a uma causa política e masculinizarem-se, sendo publicamente rechaçadas e ironizadas no meio social burguês, inclusive pela imprensa. Além do peso contraproducente desses e outros clichês mais antigos, mais tarde, as expressões acabaram por ficar ancoradas nas ações radicais dos anos 60. Estigmatizadas como essencialistas ou sexistas, isso levou (e leva) algumas artistas atuais a negarem qualquer identificação, temendo os enquadramentos e os chavões do binarismo. A recusa por rótulos, por exemplo, foi defendida por Louise Bourgeois, entre outras artistas importantes.

Sobre os problemas nas exibições das obras, a artista e investigadora Mónica Mayer ${ }^{4}$ assegura que, além da cota reduzida, há falta de critério e conhecimento da questão por parte de muitas curadorias. Ao utilizar, por exemplo, a etiqueta "arte de mulheres", num viés puramente biológico, alguns profissionais acabam por informar mal o público, pois demonstram equívocos que vão desde o desinteresse pelas questões de gênero até o desconhecimento do meio artístico - o que certamente não garante a qualidade da mostra.

Uma coisa parece certa: ser mulher não é o mesmo que ser artista feminista, e ser feminista não equivale a assumir um compromisso político em obra de arte. É preciso cuidar para que nessas análises não ocorra uma simples projeção, ou seja, ver o feminismo onde se deseja, e não onde ele de fato está.

${ }^{4}$ Mónica MAYER, 1998 
Há ainda um outro lado da questão: algumas artistas declaram ter equivalência no mercado atual aos seus contemporâneos homens e não percebem qualquer forma de sexismo em seu meio profissional, Elas entendem que esse problema está superado ou, pelo menos, não afeta suas carreiras, todavia, enquanto $50 \%$ ou mais de estudantes de arte são mulheres, a presença feminina em coletivas permanece menor.

Heloisa Buarque de Holanda ${ }^{5}$ diz que as novas artistas que não querem mais nada com o feminismo são a prova incontestável das conquistas feministas. O crítico de arte Paulo Herkenhoff ${ }^{6}$ acrescenta que a perspectiva do equilíbrio, no entanto, não deve escamotear os entraves, as contradições e as formas de discriminação da mulher que ainda existem em outros segmentos.

Enfim, o fato é que enclausurar as manifestações artísticas de mulheres, em busca de uma improvável unidade de sentido, revela uma ingenuidade imperdoável à beira de um equívoco de grandes proporções. E a impossibilidade de enquadramentos precisos e herméticos dá também às artistas poder de agir com independência, de irem e virem em seus propósitos e processos de criação e instauração.

Não resta alternativa a não ser continuar interrogando o adjetivo feminista para a arte, enquanto, a despeito de qualquer nominalismo, confirma-se a existência de uma arte que vem consolidando-se nas diferenças. Por isso mesmo, ela possui pontos de distinção a serem reconhecidos e interesses variados a serem defendidos. Esses são posicionamentos que não pretendem ser absolutos, nem de tradução única, fixos ou finais.

\section{As contradições na educação escolar: implicações pedagógicas na relação entre arte e feminismo}

A pouca visibilidade feminina recaiu nas escolas e em seus aparatos. Ao privilegiar a produção masculina, os programas para o ensino de arte não admitem ou fazem timidamente o discurso politizado das artistas. Essa é uma das contradições que ainda impregnam os espaços escolares e os colocam em defasagem a outros segmentos sociais que apontam, atualmente, maiores avanços no que diz respeito à atuação efetiva e presença das mulheres.

Não porventura, há uma carência desse discurso consumada em materiais didáticos para as aulas de arte, entre pranchas com imagens e livros, em geral, disponibilizados ao professorado, que, em contrapartida, comumente evidenciam as obras de arte de artistas homens. Logo, muitas interrogações brotaram em torno do motivo de o "fenômeno da ausência" se perpetuar nas escolas, de as artistas estarem alijadas dos programas, dos livros e das publicações didáticas. A ausência/lacuna apontada não pode ser minimizada como uma simples coincidência ou um ato despretensioso, sem intenção, apolítico, ingênuo. Há uma tendenciosa e condicionada hegemonia em torno do discurso masculino que, contagiando por longo tempo vários campos de ação, faz-se presente ainda hoje, perpetuando-se sobre docentes e discentes.

Ao se problematizar a invisibilidade das artistas nas aulas de arte, abriu-se uma discussão maior, que abarcou as seguintes questões: que tipo de arte, de ensino de arte, de escola, de formação docente pode funcionar como dispositivo estratégico e alternativo de desconstrução dessa hegemonia? Que contribuições os estudos sobre as proposições de artistas mulheres podem trazer às crianças (e não somente a elas)? Em tempos em que as políticas e agendas educacionais clamam pela equidade de gênero, como manter no

${ }^{5}$ Heloisa Buarque de HOLANDA e Paulo HERKENHOFF, 2006.

${ }^{\circ}$ HOLANDA E HERKENHOFF, 2006.

186 Estudos Feministas, Florianópolis, 23(1): 181-190, janeiro-abril/2015 
acostamento a produção dessas artistas? Como ainda é possível dar ao ensino de arte um olhar unifocal, que privilegia apenas o ponto de vista masculino, em pleno século XXI?

Para admitir a produção feminina como conhecimento a ser ensinado, é preciso pensar num tipo de ensino que contemple uma arte intercambiada com questões próprias do social. Seria um tipo de ensino que, em suas transitoriedades, fosse capaz de provocar diálogos plurais e ainda pouco vistos, que não esteja só interessado em transmitir informações convencionais, puramente manufatureiro, que, sem negações ou dissimulações, absorva para si um compromisso com o diverso, o diferente, o não dito, o interdito, o periférico e, por isso mesmo, seja capaz de colaborar na dissolução da perpetuação de um único ponto de vista e na reabilitação de outras formas de saber e poder.

Aprendemos com Michel Foucault ${ }^{7}$ que todo poder tem seus dispositivos e campos de aplicação. É fato que a força dos convencionalismos vem impregnando os currículos escolares desde o século XVI, quando a escola começa a ser configurada como "[...] máquina conservadora de repetições ou recorrências, que tem fixado formas constitutivas do humano, naturalizando-as."

Ainda com José Obregón, ${ }^{9}$ pensamos que a escola, assim como a pedagogia, segue com sua forma cristã inicial até hoje, e, como segmento comumente perpetuador de paradigmas sociais, pode-se dizer que ela seja, entre outros espaços sociais, "[...] alvo e campo de aplicação, quer dizer, onde ele [o poder patriarcal] se implanta e produz efeitos reais."10

Esse poder foi investido e segue sendo reinvestido a favor de certo discurso masculino, em níveis variados, naqueles/as que fazem parte dos núcleos de formação educacional, bem como em seus mecanismos, suas normas, seus discursos, suas ferramentas e práticas.

Guacira Louro ${ }^{11}$ reitera dizendo que a escola, ao longo da história, preocupada em disciplinar e normalizar os indivíduos, estabeleceu padrões, regulamentos e legislação capazes de separar e ordenar cada um/a e todos/as e, como em outras instâncias, utiliza estratégias sutis de dissimulação e de negação das questões de gênero (bem como da sexualidade), de difícil reconhecimento, tal o nível de naturalização alcançado.

Foucault não chega a ser fatalista quando aguça o olhar sobre os dispositivos de poder e deixa uma pista importante ao afirmar que "onde existe poder, existe resistência". ${ }^{2}$ Resistir é uma força contrária, que se opõe, que subsiste, e, partindo desse pressuposto, desmonta-se a ideia de que o poder se localiza em uns, e não em outros, que pertence a um grupo, e não a outro, e absorve-se o sentido de que ele circula, move-se, é pendular e funciona em rede.

Costurando todos esses sentidos, é possível pensar em empreender uma estratégia de resistência e subversão in loco, ou seja, organizar outra força resistente dentro dos esquemas da própria escola, no interior dos planejamentos, dos programas, da docência em arte, que busque a superação dessa contradição.

A seguir, apontamos alguns argumentos que sustentam a discussão apresentada, considerando que a adoção de um trabalho pedagógico em torno da produção de artistas mulheres na contemporaneidade, no contexto escolar, pode:

1. desacostumar os olhos das presenças naturalizadas do feminino, das composições ligadas aos conceitos classicistas e convencionais, lançando novas representações de

${ }^{7}$ Michel FOUCAULT, 1979 e 1999

${ }^{8}$ José S. OBREGÓN, 2007, p. 74.

9 OBREGÓN, 2007.

${ }^{10}$ FOUCAULT, 1979, p. 182

11 Guacira L. LOURO, 1998.

${ }^{12}$ FOUCAULT, 1999, p. 91. 
temas cotidianos e aproximados da realidade vigente, apresentando, assim, uma nova escritura visual - arte contemporânea - sintonizada com seu tempo e representativa de uma genealogia do presente;

2. desabituar a pensar a arte como objeto eterno, transcendente e fixo em um museu ou instituição cultural. Em contato com a arte de algumas artistas contemporâneas, estendese o conceito de objeto artístico para além dos modos "tradicionais", relacionando-se mais à vida pública e cotidiana;

3. deixar de pensar em "artista" como uma figura romântica, individualista, divina, dotada de um dom essencial, solitária, genial e do sexo masculino. Por outro lado, podemos comprovar a presença feminina nas artes como produções culturais legítimas, reconhecidas e qualificadas;

4. estranhar a compreensão da obra de arte como uma produção resultante somente de individualidades e sentimentalismos, mas como fruto das implicações do sujeito/artista no contexto social, político, cultural etc.;

5. servir de pretexto para abrir o diálogo sobre problemáticas sociais ao evidenciar os conflitos e dilemas embutidos nas obras, sem rodeios, escamoteios ou minimizações, como forma de enfrentamento e busca de alternativas para a superação do sexismo, das dicotomias, exclusões, invisibilidades;

6. comungar com as metas de equidades indicadas nas agendas educacionais e políticas públicas da atualidade;

7. favorecer uma multiplicidade de atividades, apropriações e "traduções" inspiradoras para as aulas, devido à grande variedade de formas, cores, materialidades, suportes, soluções plásticas, meios de expressão que geram a ampliação do repertório instrumental dos estudantes;

8. gerar uma análise conceitual artístico-estética dos aparatos, dos materiais utilizados e das inter-relações coexistentes entre várias proposições artísticas e/ou áreas de conhecimento em torno das temáticas exploradas nas obras de mulheres artistas, pois são veículos simbólicos, metafóricos, carregados de analogias e sínteses, ou seja, são multidisciplinares e multidirecionais;

9. incentivar outros modos de ser e pensar para meninos e meninas, professores e professoras, por meio da crítica aos códigos silenciados e cristalizados ou ainda pouco discutidos nas artes visuais;

10. dar acesso às diferentes manifestações artísticas produzidas por homens e mulheres artistas de vários lugares, culturas e épocas, ampliando e reforçando o direito às informações artísticas, culturais e sociais de modo mais amplo e abrangente possível;

11. dialogar com o contexto social da escola (estudantes, família, docentes e comunidade), por estas proposições artísticas tratarem de assuntos cotidianos, propiciando uma identificação com histórias de vida pessoais e acontecimentos que se relacionam aos temas em questão.

Entendemos que as poéticas visuais contemporâneas produzidas por mulheres, em suas inúmeras variáveis e mais amplamente exploradas, podem ser gatilhos detonadores de processos enraizados e servir como elementos desafiadores e desestabilizadores de paradigmas convencionais ainda persistentes em algumas práticas pedagógicas em arte. Conhecer mais sobre a produção artística feminina atrelada aos feminismos também permite a ampliação do repertório docente e, consequentemente, também do estudantil.

É preciso tomar carona na contaminação que a arte contemporânea proporciona para ousar outros modos de ensinar, outras proposições e outros desdobramentos didáticos ainda pouco explorados, mas que anunciam, desde já, resultados favoráveis ao ensino de arte, à educação e à vida. 


\section{Referências}

BARBOSA, A. M. "Arte y minorias: la mujer y el pueblo". In: CAO, M. L. F. (Ed.). Geografías de la mirada: género, creación artística y representación. Madrid: Instituto de Investigaciones Feministas de la Universidad Complutense de Madrid, 2001. p. 39-47.

BASBAUM, R. Além da pureza visual. Porto Alegre: Zouk, 2007.

CHADWICK, W. Mujer, arte y sociedad. Barcelona: Ediciones Destino, 1999.

COSTA, C. L. "Paradoxos do gênero". Gênero, Niterói, v. 4, n. 1, p. 169-177, 2000.

COUTINHO, A. S. Poéticas do feminino/feminismo na arte contemporânea: transgressões para o ensino de artes visuais em escolas. 2010. 252 p. Tese (Doutorado em Estudos da Criança) - Universidade do Minho, Braga, 2010.

"Quando a arte produzida por mulheres desafia o ensino de arte". Diálogo com a Arte, Campinas, n. 2, p. 17-28, 2011.

FOUCAULT, M. História da sexualidade l: a vontade de saber. Rio de Janeiro: Graal, 1999. Microfísica do poder. Rio de Janeiro: Graal, 1979.

HOLANDA, H. B.; HERKENHOFF, P. Manobras radicais. São Paulo: Centro Cultural Banco do Brasil, 2006.

LOPONTE, L. Gruppelli. Docência artista: arte, estética de si e subjetividades femininas. 2005. 207 p. Tese (Doutorado em Educação)-Universidade Federal do Rio Grande do Sul, Porto Alegre, 2005.

"Gênero, visualidade e arte: temas contemporâneos para educação". In: ICLE, G. (Org.). Pedagogia da arte: entre-Iugares da criação. Porto Alegre: UFRGS, 2010. p.149163.

"Pedagogias visuais do feminino: arte, imagens e docência". Currículo sem Fronteiras, [S.I.], v. 8, n. 2, p. 148-164, jul./dez. 2008. Disponível em: <http://www.curriculosemfronteiras. org/vol8iss2articles/loponte.pdf>. Acesso em: 23 nov. 2012.

. "Sexualidades, artes visuais e poder: pedagogias visuais do feminino". Revista Estudos Feministas, Florianópolis, v. 2, n. 10, p. 283-300, 2002.

LOURO, Guacira L. Segredos e Mentiras do Currículo: Sexualidades e Gênero nas Práticas Escolares. In Silva, Luiz H. (org.) A Escola Cidadã no Contexto da Globalização. Petrópolis: Vozes, 1998.

MCCAUGHAN, E. J. "Navegando pelo labirinto do silêncio: artistas feministas no México". Revista Estudos Feministas, Florianópolis, v. 1, n. 11, p. 89-112, 2003.

MAYAYO, P. Historias de mujeres, historias del arte. Madrid: Ediciones Cátedra, 2003.

MAYER, Mônica. De la Vida y el Arte como Feminista. Parte I y II. N. Paradoxa: International Feminist Art Journal, n.8, nov., 1998. Disponível em: <http://web.ukonline.co.uk/ n.paradoxa/mayer.htm > . Acesso em: 19 out. 2009.

NOCHLIN, L. "Why have there been no great woman artists?" In: NOCHLIN, L. Women, art and power and other essays. Boulder: Westview Press, 1971. p. 145-178.

"Why have there been no great women artists? Thirty years after". In: ARMSTRONG, C.; OBREGÓN, J. S. "La escuela como dispositivo estético". In: FRIGERIO, G.; DIKER, G. (Org.). Educar: (sobre) impresiones estéticas. Buenos Aires: Del Estante Editorial, 2007. p. 73-86. RUSH, M. Novas mídias na arte contemporânea. São Paulo: Martins Fontes, 2006.

SILVA, L. H. (Org.). A escola cidadã no contexto da globalização. Petrópolis: Vozes, 1998. p. 33-47.

Gênero, sexualidade e educação. Petrópolis: Vozes, 1997.

TOMKINS, C. Duchamp: uma biografia. São Paulo: Cosac Naif, 2004.

ZEGHER, C. (Ed.) Women artists at the millenium. Cambridge: Massachusetts Institute of Technology, 2006. p. 21-32. 
[Recebido em outubro de 2014 e aceito para publicação em novembro de 2014]

\section{Visual Arts and Feminisms: Pedagogical Implications}

Abstract: What is the point of dealing with the relationship between the visual arts and Feminisms today? What are the possible effects of this discussion for contemporary art teaching? These and other questions permeate this article, which intends to bring to the fore a still marginal topic, almost invisible amidst our main pedagogical concerns related to art and education, arising also from the few or scarce theoretical texts about it, especially the ones written in Portuguese. The discussions presented in this article emerge mainly from researches made by Loponte (2002, $2005,2008,2010)$ and Coutinho $(2010,2011)$. By raising questions that intertwine the visual arts and Feminisms or the idea of art pervaded by Feminist intentions, we propose a more attentive view of pedagogical practices that are not exempt from the inclusion of such discussions, but still seem to be lethargic around these and more provocative and deconditioning approaches in the school context. We initially present the discussion intertwining contemporary art, Feminisms and female artists, indicating some of the ways of thinking around this relationship. We also approach the erosion of the Feminist adjective as related to the visual arts to, finally, point out pedagogical contradictions and implications in the connections between art and Feminism. In this sense, we intend to call attention to the need of critical analyses involving a work turned towards education about art produced by contemporary women artists in the school environment, presenting a few arguments in favor of this educational task.

Key Words: Art; Women artists; Education; School. 